\title{
LAS REDES MERCANTILES DEL TRÁFICO ILEGAL ENTRE NUEVA ESPAÑA Y FILIPINAS, 1653-1664
}

\author{
GUILLERINA del VALLE PAVÓN \\ INSTITUTO DE INVESTIGACIONES DR. JOSÉ MARÍA LUIS MORA
}

ORCID iD: 0000-0003-3647-1827

\begin{abstract}
RESUMEN
En el presente ensayo se analizan las prácticas de negociación ilícita que los virreyes duque de Alburquerque (1653-1660) y conde de Baños (1660-1664), así como sus parientes y allegados, realizaron en el comercio transpacífico, con el apoyo de los mercaderes de la ciudad de México, cuando dicho tráfico había decaído.

PALABRAS CLAVE

México, Filipinas, comercio, redes, siglo XVII, Pacífico.

\section{THE COMMERCIAL NETWORKS OF ILLEGAL TRAFFIC BETWEEN NEW SPAIN AND THE PHILIPPINES, 1653-1664}

\begin{abstract}
This essay analyzes the illegal negotiation practices that the viceroys Duke of Alburquerque (1653-1660) and Count of Baños (1660-1664), as well as their relatives and close friends, carried out in the trans-Pacific trade, with the support of the merchants of Mexico City when that such traffic had declined.
\end{abstract}

\section{KEYWORDS}

México, Philippines, trade, networks, seventeenth century, Pacific. 

a monarquía católica impuso en el Imperio hispánico una política comercial restrictiva. Guiada por doctrinas mercantilistas, en las últimas décadas del siglo XVI y los primeros años del XVII, introdujo férreas limitaciones en la carrera de Filipinas con el doble propósito de impedir el flujo de plata americana a Asia y proteger el monopolio del Consulado de Sevilla. El comercio transpacífico se estableció entre los puertos de Manila y Acapulco con topes máximos en el número de navíos y su tonelaje, así como en el volumen de mercancías y plata que podían negociar cada año. ${ }^{1}$ Los bienes orientales unicamente se debían vender en Nueva España y remitirse a Sevilla, se prohibió de manera terminante expedirlos al Perú, Tierra Firme, Guatemala y el resto de Indias. Para favorecer la economía y el poblamiento del enclave filipino, los residentes en Manila debían encabezar dicho comercio, por lo que no podían operar como encomenderos de los mexicanos. ${ }^{2}$ Esta normatividad que rigió durante el siglo XVII, provocó permanentes resistencias y negociaciones.

Los virreyes de Nueva España plantearon, desde un principio, la imposibilidad de cumplir con la reglamentación mencionada y sugirieron incrementar los gravámenes sobre el tráfico comercial, en lugar de limitarlo. ${ }^{3}$ Esto obedecía, en gran medida, a que dichos mandatarios negociaban de manera ilegal con Filipinas y los puertos del Pacifico Hispanoamericano. La historiografía contemporánea ha mostrado evidencias de su participación en dicho tráfico con el apoyo de los mercaderes que se asociaban en el Consulado de la ciudad de México, cuando menos, desde la década de $1620 .{ }^{4}$ En particular, el documentado estudio de Pierre Ragon sobre el virrey conde de Baños proporciona información sobre su participación y la de otros oficiales reales en las negociaciones con Filipinas. ${ }^{5}$

1 Sólo podían zarpar de Manila dos embarcaciones de 300 toneladas, con mercancías por valor de 250,000 pesos y retornar de Acapulco con 500,000 pesos de plata. Recopilación de Leves de los Repnos de Indias, Madrid, Ivlian de Paredes, año de 1681. Facsímile en México, Miguel Ángel Porrúa, 1987, libro IX, tit. 45, leyes i, vi, xv, lxi, xxxxiiii.

2 Ibídem., libro IX, tit. 45, leyes v, lviii, lxiiii, lxviiii; Reales cédulas dadas en Valladolid el 31 de diciembre de 1604, en Actas de Cabildo, México, 2 de diciembre de 1605. Archivo Histórico de la ciudad de México (A.H.C.M.), v. 646-a. Sobre el papel de los mercaderes de México en el comercio Pacífico, en el periodo señalado, y la constitución de su Consulado, véase VALLE PAVÓN, Guillermina. Los mercaderes de México y la transgresión de los límites al comercio Pacífico en Nueva España, 1550-1620. Revista de Historia Económica / Journal of Iberian and Latin American Economic History, La Economía en tiempos del Quijote, v. XXIII, número extraordinario, Madrid, 2005, pp. 213-240.

3 Así lo hicieron los virreyes conde de Monterrey (1595-1603), marqués de Montesclaros (1603-1607) y, Luis de Velasco (1607-1611). Ibídem

4 El virrey marqués de Cerralvo (1624-1635) se valió de Cristóbal Bonilla Bastida y de su yerno Antonio Urrutia de Vergara para contratar de manera encubierta bienes asiáticos. Es muy posible que Urrutia de Vergara prestara servicios similares a otros virreyes, como al conde de Salvatierra (1642-1648), quien le redujo parte de los gravámenes que adeudaba por la circulación de mercancías. HOBERMAN, Louisa Schell. Mexico's merchant elite, 1590-1660. Silver, state and society. Durham: Duke University Press, 1991, PP. 178-179; ISRAEL, Jonathan I. Razas, clases sociales $\gamma$ vida política en el México colonial 1610-1670. México: Fondo de Cultura Económica, 1980, pp. 107, 181.

5 RAGON, Pierre. Pouvoir et corruption aux Indes espagnoles. Le gouvernement du comte de Baños, vice-roi du Mexique, París, Berlin, 2016, pp. 106-118 y “¿Abusivo o corrupto? El conde de Baños, virrey de Nueva España (1660-1664): de la voz pública al testimonioen derecho", en Mérito, venalidad y corrupción en España $\gamma$ América, siglos XVI-XVIII, Pilar Ponce y Francisco Andújar, (coords.), Madrid, Editorial Albatros, 2016, pp. 267-282. 
El propósito del presente ensayo radica en analizar las prácticas de negociación ilícita que los virreyes duque de Alburquerque (1653-1660) y conde de Baños (1660-1664), así como sus parientes y allegados, realizaron en el comercio transpacífico, con el apoyo de los mercaderes de la ciudad de México. Cabe señalar que abarcamos unos años en los que el comercio entre Acapulco y Manila había decaído. Las medidas introducidas por el visitador Pedro de Quiroga y Moya en 1636 para limitar el contrabando, que había aumentado notablemente en los últimos años, clausuraron el comercio con el Perú, de donde procedía gran parte de la plata destinada al Oriente, circunstancia que, junto con la eliminación y destierro de los comerciantes judeoconversos, ${ }^{6}$ provocaron la contracción de las inversiones de los mercaderes de México. ${ }^{7}$

\section{LOS MERCADERES DE MÉXICO EN EL COMERCIO TRANSPACÍFICO}

A pesar de que los mercaderes de la ciudad de México tenían prohibido enviar capitales a Manila para contratar mercancías, mantuvieron bajo su control dicho comercio gracias a su poder financiero, ya que concentraban gran parte de la plata producida en Nueva España. Para disponer del metal blanco, habilitaban a los productores mineros y compraban en grandes cantidades la plata del rescate que no había pagado el derecho del quinto. ${ }^{8}$ Los mercaderes la destinaban esta clase de plata al tráfico ultramarino que se realizaba de manera clandestina. A mediados del siglo XVII se calculaba que la extracción de plata sin quintar representaba una tercera parte de la producción del virreinato, fenómeno que aumentó con el paso de los años. ${ }^{9}$ Gran parte de la plata sin quintar se destinaba al mercado asiático en donde tenía mayor valor que en Europa y, por lo tanto, un poder de compra más elevado.

6 GARCÍA DE LEÓN, Antonio. La malla inconclusa. Veracruz y los circuitos comerciales lusitanos en la primera mitad del siglo XVII. IBARRA, Antonio, VALLE, Guillermina del (coord.). Redes sociales e instituciones comerciales en el Imperio Español, siglos XVII a XIX. México: UNAM, Instituto de Investigaciones Dr. José María Luis Mora, 2007, pP. 41-83.

7 HOBERMAN, op. cit., pP. 178, 219-220; SERRANO HERNÁNDEZ, Sergio. "Building an Empire in the New World. Taxes and Fiscal Policy in Hispanic America during the Seventeenth Century", Madrid, tesis para obtener el grado de doctor por la Universidad Carlos III de Madrid, 2020, pp. 387-397. Chaunu mostró que en las décadas de 1640 y 1650 el comercio de Filipinas se contrajo notablemente, a partir del análisis de los ingresos fiscales que pagaron en el puerto de Manila las embarcaciones procedentes de otros puertos asiáticos. CHAUNU, Pierre. Las Filipinas y el Pacífico de los ibéricos. Siglos XVI, XVII y XVIII. México: Instituto Mexicano de Comercio Exterior. [1ª. edición 1960], 1974, Pp. 150159.

8 Se llamaba plata del rescate a la que era producto de las pepenas de los trabajadores mineros y a la que extraían los pequeños mineros, las cuales eran fundidas en pequeños hornos y no se ensayaban, por lo que podía ser de baja ley. BAKEWELL, P. J. Minería y sociedad en el México Colonial. Zacatecas (15461700). México: Fondo de Cultura Económica, 1976, p. 252.

9 En 1663 el principal oidor de la Audiencia observó que la extracción de plata que no había pagado derechos se había incrementado. Ibídem., pp. 252-254. 
Para los mercaderes de México el comercio con Filipinas era sumamente redituable, tanto porque la plata tenía un elevado poder adquisitivo, como porque su poder financiero les daba una posición dominante. En cambio, en el tráfico de la flotas operaban, principalmente, como comisionistas de los cargadores andaluces. ${ }^{10}$ En la permisión de la Carrera Filipina se había concedido a los vecinos de las islas el envío a Acapulco de 250,000 pesos en mercancías, sin embargo, eran los mercaderes de México quienes compraban la mayor parte, a pesar de la reiteración de las órdenes en dicho sentido. ${ }^{11}$ Para adquirir bienes asiáticos en el archipiélago y acceder a las boletas de carga de las naos que se dirigían a Acapulco, dichos actores enviaban personas de su confianza a residir en Manila, al menos por ocho años, de acuerdo con lo establecido por la legislación. ${ }^{12}$ También se asociaban con residentes de dicha ciudad, los cuales tenían poca liquidez, porque en el archipiélago no había minería, la producción agrícola era realizada por los nativos y la artesanal por los chinos. Los socios de los mercaderes de México eran miembros de la administración civil y eclesiástica, del ayuntamiento, empleados del tribunal de la Inquisición y, sobretodo, militares. ${ }^{13}$ Esto se explica porque la economía del archipiélago dependía, en lo fundamental, del comercio transpacífico y del auxilio fiscal que recibía de Nueva España.

Al igual que en la Carrera de Indias, en el comercio Pacífico circulaban cantidades de plata y mercancías muy superiores a lo permitido, que se transportaban en los galeones fuera de registro. Existen diversas estimaciones para los años anteriores al periodo que abordamos, en las que se calcula que el contrabando duplicaba, al menos, los límites establecidos. Y a partir de la década de 1630 los caudales remitidos a Manila pudieron haber ascendido hasta los cuatro o seis millones de pesos, cuando el tope máximo era de 500,000 pesos. ${ }^{14} \mathrm{El}$ contrabando representaba un gran perjuicio para la corona, ya que, , además de propiciar la fuga de plata al Oriente, evadía el pago de los derechos reales.

Para transportar la plata y las mercancías fuera de los registros oficiales, los mercaderes de México tejían redes de connivencia con los castellanos y oficiales reales de los puertos de Aca-

10 VALLE PAVÓN, Guillermina. Contrabando, negocios y discordias entre los mercaderes de México y los cargadores peninsulares, 1670-1711. Studia historica, Historia moderna, v. 42, no. 2, 2020, pp. 115-143.

11 Al respecto puede verse la real orden dada en Madrid el 23 de mayo de 1630. Recopilación, op. cit., libro IX, tit. 45, ley xxxxv. VALLE PAVÓN, "Mercaderes de México...".

12 Quienes fueran a residir a Manila podían llevar sus propias haciendas. Cédulas dadas en Valladolid, el 2 de diciembre de 1604 y en El Pardo, el 10 de noviembre de 1608. Recopilación, op. cit., libro IX, tit. 45, leyes xii y xxix.

13 HOBERMAN, op. cit., Pp. 63, 175-177; VALLE PAVÓN, "Mercaderes de México..."; HUERTA, María Teresa. Redes mercantiles en torno a la plata en el norte minero novohispano. Segunda mitad del siglo XVII, en IBARRA, Antonio, VALLE, Guillermina del (coords.). Redes sociales e instituciones comerciales en el Imperio Español, siglos XVII a XIX, México: UNAM, Facultad de Economía; Instituto de Investigaciones Dr. José María Luis Mora, 2007, pp. 85-116.

14 HOBERMAN, op. cit., en particular el cuadro 21, pp. 218-220; VALLE PAVÓN, "Mercaderes de México...". 
pulco y Cavite, que supervisaban la carga y el desembarco de los galeones. Como los oficiales de los galeones y los capitanes de los destacamentos que se reclutaban para la defensa del archipiélago podían cargar de manera subrepticia caudales y bienes no declarados, los mercaderes concertaban acuerdos con ellos para que fungieran como sus agentes o encomenderos. Asimismo, podían conseguir que se colocara a sus parientes y allegados como generales, almirantes y sargentos mayores de los galeones, así como capitanes de las compañías de infantería que se destinaban a las islas. Otra estrategia consistía en desembarcar las mercancías no registradas antes de llegar a Acapulco, en las costas de Nueva España y Guatemala. Las prácticas mencionadas eran posibles, en gran medida, porque el virrey, junto con otros funcionarios de la administración civil y eclesiástica, estaban involucrados en el contrabando.

Aunque el comercio con Filipinas era sumamente rentable, acarreaba grandes riesgos. En la travesía se enfrentaban vientos y corrientes contrarias, tormentas, huracanes, el acoso de piratas asiáticos y europeos, por lo que muchos galeones naufragaron y se perdieron. Además, el arribo y la partida de Manila eran complicados porque se tenia que navegar entre las islas con peligro de atorarse en los bajos y golpear contra los arrecifes. La ruta de Filipinas a Acapulco era particularmente peligrosa por su larga duración, ya que, si la travesía se prolongaba más de lo previsto, se podían padecer hambre, escorbuto y otras enfermedades. También se corría el peligro de que fueran incautados los capitales o las mercancías que se traficaban de manera ilícita o, peor aun, que los virreyes, sus familiares y criados, otros funcionarios y socios no restituyeran los caudales prestados.

\section{EL VIRREY DUQUE DE ALBURQUERQUE Y SU PODEROSO LINAJE}

Cuando los virreyes se hacían cargo de la administración de Nueva España, establecían vínculos estrechos con algunos de los mercaderes de plata de la ciudad de México, los cuales se convertían en los hombres de su confianza. Al igual que sus antecesores, Francisco Fernández de la Cueva y Enríquez, el virrey octavo duque de Alburquerque (1653-1660), participó de manera subrepticia en la contratación de mercancías orientales . Para ello nombró general de la nao a su sobrino Pedro de Villarroel y de la Cueva, y con el apoyo del mercader Juan Vásquez de Medina, adquirió e introdujo a la ciudad de México bienes orientales cargados en 130 mulas, que almacenó en su casa y se hizo cargo de su contratación. Vásquez de Medina, quien fue procurador de la ciudad de Manila, era originario de la villa de Cuellar, en Segovia, que formaba parte del marquesado de Cuellar, que detentaba el duque de Alburquerque, por lo que 
por lo que el mercader y sus familiares eran sus vasallos. De aquí que Vásquez de Medina fuera "confidente" del virrey y que este le confiara los negocios que realizaba de manera ilícita. ${ }^{15}$

Los familiares y criados del duque realizaron negocios en Filipinas asociados con el mercader Antonio Urrutia de Vergara, originario de Vergara, en Guipúzcoa, quien había sido designado "maestre de campo" de una compañía de infantería de la ciudad de México, por sus servicios a la corona y el pago de 12,000 pesos. Este empleo le permitía nombrar a los oficiales de los galeones y a los capitanes de las compañías que se enviaban a Filipinas para su defensa, casi cada año, circunstancia que favorecía sus negocios. ${ }^{16}$ Urrutia de Vergara se asoció, en 1655 , con Pedro Fernández Villarroel y de la Cueva, otro sobrino de Alburquerque, al que nombró general del galeón de Manila y le prestó, cuando menos, 6,000 pesos. Al año siguiente, Urrutia de Vergara formó otra sociedad con su yerno, el capitán Antonio Alfonso Flores de Valdés y con Cristóbal de Santillán y Mendoza, yerno de Antonio de Lara Mogrovejo, quien fungía como alcalde del crimen de la audiencia de México. En total invirtieron 15,000 pesos, de los cuales cada uno aportó 5,000 pesos. ${ }^{17}$ Lara Mogrovejo había sido oidor de la audiencia de Guatemala por casi veinte años, de modo que era posible que estuviera involucrado en la redistribución de los bienes asiáticos en los puertos de la Mar del Sur.

En 1655, la nao San Francisco Javier, zarpó de Acapulco en marzo, pero naufragó al llegar a la bahía de Borongán, en la isla de Samar. Gran parte de los pasajeros y la tripulación se salvaron, auque la carga se hundió. De Manila se despachó un auditor para supervisar las operaciones de salvamento. Luego del rescate, se encontró que el navío llevaba capitales por cerca de 1,180,900 pesos, de los cuales 239,000 correspondían al auxilio fiscal de Nueva España, poco más de 418,300 pertenecían al comercio legal y 523,500 pesos más, se habían cargado de manera ilicita. Poco más del doble de la plata para contratar se había enviado fuera de registro. El sigilo con que el duque de Alburquerque manejó el rescate de los fondos que transportaba la nao y su destino, dio lugar a que Urrutia de Vergara se enfrentara con su sobrino, Fernández de Villarroel, y acusara al virrey de que había tratado de engañarlo para no reconocer sus derechos. El duque recusó todos los procedimientos que Urrutia de Vergara presentó en su contra ante la audiencia de México. No obstante, el poderoso

15 "Sentencia del Consejo de Indias sobre el duque de Alburquerque, 12 de mayo de 1665", en HANKE, Lewis, (ed.). Los virreyes españoles en América durante el gobierno de la casa de los Austria. Madrid: Ed. Atlas, 1977, (Biblioteca de Autores Españoles), vol. IV, p. 179; Cédula del 8 de mayo de 1660. AGN, AHH, 599-3.

16 HOBERMAN, op. cit., p. 156; FERNÁNDEZ BULETE, Virgilio. El poder del dinero en el México del siglo XVII: el financiero don Antonio Urrutia Vergara. Estudios sobre América: siglos, XVI-XX. Sevilla, AEA, 2005, Pp. 653-672; RAGON, op. cit., pp. $113-115$.

17 Ibídem., p. 116. 
negociante, a quien el duque reconoció como "el comerciante más grande de las Indias", entonces estaba en la cúspide de su carrera, era maestre de campo, caballero de la orden de Santiago, familiar de la Inquisición y estaba emparentado con miembros la nobleza, por lo que acusó a Alburquerque ante el juez que practicó su juicio de residencia y presentó el asunto ante el Consejo de Indias. ${ }^{18}$

Como consecuencia de la mencionada denuncia, en 1661 se emitió una real cédula que ordenó la obligación de admitir las causas y pleitos relativos al extravío de plata o géneros que estaba prohibido comerciar, aunque se tratara de gobernadores, oficiales de la real Hacienda y cualesquiera otros ministros. Precisó que se debían imponer las penas establecidas, sin que los reos puedan "...oponer privilegio alguno de fueros, ni serles admitida, aunque sean caballeros de las órdenes militares, capitanes, soldados de cualesquiera milicias oficiales, titulares, familiares de la Santa Inquisición, ministros de la Santa Cruzada y otros algunos..." Y, dadas las dificultades para averiguar la culpa de los malhechores en delitos de tan dificultuosa provanza, se debía dar fe y crédito a las noticias que presentaran los ministros y otras personas. ${ }^{19}$ Sin embargo, como veremos a continuación, dichas medidas tenían muy poco impacto sobre la actividad comercial.

Urrutia de Vergara se ganó la animadversión del sucesor del duque de Alburquerque, su primo el conde de Baños, quien tomó su partido. Una vez que se hizo cargo del gobierno de Nueva España, el conde hostigó al mercader, sus parientes y aliados. Cuando Urrutia Vergara prestó dinero a un minero de Zacatecas para comprar azogue, el secretario del virrey, trató de aumentar el precio del metal líquido y suspendió la entrega, lo que obligó a los interesados a hacer múltiples diligencias para conseguirlo. Baños también impidió que Urrutia Vergara enviara correspondencia a Castilla, aun cuando el mercader hizo llegar sus pliegos al puerto de Veracuz. Y, con un motivo banal, desterró al maestre de campo al pueblo de Texcoco, fuera de la ciudad de México, y a tres ministros que le eran favorables a lugares más lejanos, además de multar al primero con 6,000 pesos y a los oficiales reales con 500 pesos a cada uno. El Consejo de Indias se opuso a la decisión del virrey, le mandó restituir las plazas y el dinero de las

18 Ibídem., p. 110, 114-117; ISRAEL, op. cit., p. 257. En su juicio de residencia, Alburquerque fue condenado por treinta y un cargos, por lo que se le impuso el pago de 50,000 pesos para los costos y salarios del juicio. El Consejo de Indias revocó todos los cargos, pero, al parecer, Alburquerque no logró que se restituyera el dinero que había pagado. BAEZA MARTíN, Ascensión. Biografía de Francisco Fernández de la Cueva y Enríquez, XVIII duque de Alburquerque, www.dbe.rah. es/biografías.

19 Se hace referencia a la real cédula del 4 de noviembre de 1661 en el nombramiento de gobernador de Filipinas para Martín de Ursúa y Arizmendi, conde de Lizárraga. Real cédula, Madrid, 19 de agosto de 1704. Archivo General de la Nación (AGI), Pasajeros a Indias, Contratación, 5463, N.68, 1706. 
penas que les había impuesto. Todo esto y más, fue denunciado por Urrutia Vergara al juez de residencia de Baños. ${ }^{20}$ Además, luego de que la junta general de real Hacienda acordó conceder a dicho mercader en arrendamiento el ramo de naipes por 70,000 pesos anuales, el virrey se opuso y colocó la renta bajo administración real, al tiempo que consiguió que un vecino de la ciudad de Oaxaca hiciera una postura por 80,000 pesos, lo que obligó al mercader a elevar la suya hasta 96,000 pesos. $^{21}$

\section{EL VIRREY CONDE DE BAÑOS “UN MERCADER MÁS EN EL REINO”}

El situado o socorro fiscal de Nueva España a Filipinas solo se podía enviar cuando llegaban naos de Filipinas, porque en el virreinato no se disponía de embarcaciones. Durante la administración del duque de Alburquerque los viajes del galeón fueron muy irregulares, en parte debido a la pérdida del navío San Francisco Javier, en 1655. Y, al parecer, en 1659 la nao que iba de Acapulco a Manila, en la bahía de Borongán fue arrastrada a los arrecifes y perdió su carga. ${ }^{22}$ Desde 1656, las autoridades de la ciudad de Manila expusieron al Consejo de Indias las carencias que padecían, pidieron que se regularizara el envío del situado novohispano y se tomaran medidas urgentes para reactivar el comercio con Acapulco. ${ }^{23} \mathrm{El}$ conde de Baños tomó posesión de su cargo en septiembre de 1660, con instrucciones de dar prioridad al socorro de Filipinas, que se encontraba en un "estado miserable", y revitalizar el comercio transpacífico. El virrey encontró que hacía más de dos años que no se tenían noticias de las islas, debido a la falta de navíos. ${ }^{24}$

La crisis del tráfico con Filipinas era tal, que poco después de la llegada del conde de Baños, el mercader Juan Vásquez Medina, entonces procurador de la ciudad de Manila, pidió al duque que diera cumplimiento a una cédula de mayo de 1660 que se había emitido para revitalizarlo. El mercader se había enriquecido en las negociaciones con Filipinas, en par-

\footnotetext{
20 Urrutia Vergara denunció al virrey de todo lo expuesto y de que, cuando le había solicitado dos alcaldías mayores, una para su nieto, el conde de Peñalba, y otra para su yerno Rodrigo de Vivero, hermano del conde de Orizaba, les había concedido las de Chalco y Querétaro, respectivamente, a cambio de tres pulseras de perlas y tres cadenas de oro de filigrana, por valor de 6,000 pesos. Baños, al igual que sus antecesores puso a la venta un importante número de alcaldías mayores y corregimientos. Sentencia del Real Consejo de Indias sobre el Conde de Baños, en HANKE, op. cit., vol. IV, PP. 216-298; ISRAEL, op. cit., p. 265.

21 Papel en que se refieren los servicios que hizo a S.M. el conde de Baños, Juan de Leyva y de la Cerda, Ca. 1660, en HANKE, op. cit., vol. IV, pp. 182-198.

22 www.todoavante.es

23 Carta del cabildo secular de Manila, 15 de julio de 1656. A.G.I., Filipinas 31, no. 40.

24 Papel en que se refieren los servicios que hizo a S.M. el conde de Baños, Juan de Leyva y de la Cerda, Ca. 1660, en HANKE, op. cit., vol. IV, p. 189; PRIETO LUCENA, Ana María. Filipinas durante el gobierno de Manrique de Lara 1653-1663. Sevilla: Escuela de Estudios Hispanoamericanos, Sevilla, 1984, pp. 22, 36-37.
} 
ticular, cuando había fungido como hombre de paja del virrey duque de Alburquerque. ${ }^{25}$ El real mandato hacía referencia a la petición que habían hecho los vecinos de Filipinas al soberano para que autorizara a los residentes de Nueva España a completar los 500,000 pesos para dicho comercio, porque ellos no podían hacerlo. El monarca mandó al virrey consultar al cuerpo mercantil de la ciudad México sobre el asunto, discutirlo en junta general de real Hacienda y enviar los votos singulares para que el Consejo de Indias tomara una resolución. Leyva y de la Cerda mandó al fiscal y a un oidor que pidieran el parecer del consulado, ${ }^{26}$ aunque no sabemos como se resolvió el asunto.

Es muy probable que desde un principio el virrey hubiera querido obtener beneficios del redituable comercio oriental, mediante el cobro de gratificaciones o comisiones por las mercancías que arribaban fuera de registro. Como el galeón de Manila solía llegar al puerto de Acapulco en el invierno, a fines de 1661 y principios de 1662, Baños designó como visitador de los navíos cuyo arribo se esperaban, a su criado, Tomás de Alarcón. ${ }^{27}$ Alarcón y sus ministros se dirigieron al puerto de Acapulco sin tener noticia del arribo de las naos, las cuales no aparecieron, por lo que tuvieron que retornar a la capital sin haber cumplido su comisión. ${ }^{28}$ En abril de 1662 llegó a México la noticia de que, finalmente, había arribado a Acapulco la embarcación capitana San José. Esta vez el conde nombró visitador del galeón a otro de sus criados, Pedro Fernández Zorrilla. ${ }^{29}$ Sin embargo, la nao llegó en muy mal estado, luego de una accidentada y larga travesía, como consecuencia de la cual, casi toda la tripulación enfermó de escorbuto, lo que ocasionó la muerte de 101 personas de las 115 que iban a bordo. Entre los difuntos se encontraba el general Cristóbal Velázquez de Lorenzana que comandaba el navío. ${ }^{30}$ El visitador no hizo las diligencias para la manifestación

25 La enorme fortuna que acumuló Vásquez de Medina, le permitió, en 1663, comprar en remate el oficio de tesorero de la casa de moneda para su primogénito, por 300,000 pesos. GUIJO, Gregorio M. de. Diario 1648-1664, Edición y prólogo de Manuel Romero de Terreros. México: Editorial Porrúa, 1952, t, II, p. 193; HUERTA, op. cit., p. 111.

26 Real cédula del 8 de mayo de 1660. Archivo General de la Nación (A.G.N.), Archivo Histórico de Hacienda, A.H.H., 519-3.

27 El virrey también nombró a Alarcón alcalde mayor de Tepeaca con la agregación del corregimiento de Santiago Tecali, contador de menores en la ciudad de Puebla y administrador de los novenos del obispado de Puebla, sin pedirle la fianza correspondiente, por lo que quedó a deber 749 pesos. Sentencia del Real Consejo de Indias sobre el Conde de Baños, en HANKE, op. cit., vol. IV, pp. 216-298.

28 El conde fue acusado de que haber pagado poco más de siete mil pesos a dicho visitador y a sus ministros, sin que hubieran cumplido su comisión, y de haberles dado salarios excesivos a cuenta de la real hacienda, cuando debían haberse cargado a los productos de las "condenaciones y descaminos" que debían encontrar en la visita. Sentencia del Real Consejo de Indias sobre el Conde de Baños, en HANKE, op. cit., vol. IV, 216-298.

29 El virrey designó a Fernández Zorrilla alcalde mayor de Teutila. Sentencia del Real Consejo de Indias sobre el Conde de Baños, Ibídem. 216-298.

30 HERRERA REVIRIEGO, José Miguel. Acapulco, centro de comunicaciones: comercio consumo y corrupción en los galeones de Manila de mediados del siglo XVII. Fòrum de recerca, no. 16, 2011, pp. 103-118. 
de las mercancías, posiblemente porque llegaron mojadas y en mal estado, además de que habían fallecido los consignatarios que venían a su cargo, por lo que no hubo "efectos de condenaciones y descaminos". 31

El virrey pudo reestablecer el contacto con el archipiélago hasta 1662, luego de conseguir en el puerto de El Realejo (Nicaragua) una pequeña embarcación de 230 toneladas, denominada San Damián. El 5 de abril de 1662 remitió a Manila 156,000 pesos, diez compañías con un total de 150 infantes armados y algunos religiosos, lo que importó cerca de 400,000 pesos del situado. ${ }^{32}$ Leyva y de la Cerda designó como general del patache a Luis Roche, su criado, y almirante a Manuel de Alarcón, quienes llevaron a Manila por cuenta del virrey más de 70,000 pesos para emplearlos en géneros y mercaderías asiáticas. El virrey, además de contratar de manera ilícita, contravenía la legislación que prohibía expresamente a los oficiales de las naos cargar en su cabeza, ni la de otros, pena de "privación perpetua de dichos oficios" y de la pérdida de la hacienda que cargaran. ${ }^{33}$ El conde recibió dichos caudales en préstamo del mercader Domingo de Cantabrana, uno de los principales mercaderes de México, quien los remitió a su encomendero en Acapulco para embarcarlos. ${ }^{34}$

Domingo de Cantabrana, mercader originario de Santo Domingo de la Calzada, en La Rioja, se destacó por encargarse de la acuñación de la plata del erario virreinal ${ }^{35}$ y por su influencia en el cuerpo mercantil, del que fue cónsul en 1655-1656. El prominente mercader se transformó en el "allegado y confidente" de Baños, a quien recibía con su familia en su huerta de San Cosme, en las afueras de la capital. Cantabrana favorecía los negocios que realizaban el conde, su mujer y su primogénito, al otorgarles financiamiento y operar como su testaferro. Cuando el hijo del virrey, Pedro de Leyva, fue nombrado alcalde mayor de Villa Alta, lo habilitó con 117,000 pesos para realizar tratos, granjerías y “aprovechamientos" con los indios de su jurisdicción. En reciprocidad, el conde designó al sobrino de Cantabrana alcalde mayor

31 Por tal motivo, se tuvieron que pagar a Fernández Zorilla y sus ministros 1,917 pesos de los fondos de la real Hacienda, en contravención a las reales cédulas. Baños fue condenado a restituir a la real Hacienda los 8,974 pesos que se habían pagado a los dos visitadores y sus ministros, pero la sentencia se redujo a 1,000 pesos. Sentencia del Real Consejo de Indias sobre el Conde de Baños, en HANKE, op. cit. 216-298.

32 Papel en que se refieren los servicios que hizo a S.M. el conde de Baños, Juan de Leyva y de la Cerda, Ca. 1660, en HANKE, op. cit., p. 189; PRIETO LUCENA, op. cit., p. 37.

33 Recopilación, op. cit., libro IX, tit. 45, ley xxxxviii.

34 El virrey fue acusado de haber nombrado por almirante del navío San Damián a Manuel de Alarcón, con 1,757 pesos de salario, cuando ya contaba con las plazas de general, sargento mayor y capitanes, únicas que se requerían en los años que sólo había un galeón. Es posible que dicho Manuel fuera pariente de Tomás de Alarcón, a quien, como vimos, Baños había designado visitador de los galeones que se esperaban a fines de 1661 e inicios de 1662 . Sentencia del Real Consejo de Indias sobre el Conde de Baños, en HANKE, op. cit. 216-298; GUIJO, op. cit., t. II, 1852, p. 166. 35 HOBERMAN, op. cit., pP. 67. 
de Mestitlán de la Sierra. El mercader también obtuvo jugosas comisiones al operar como mediador del virrey en la venta y renovación de diversos corregimientos y alcaldías mayores. ${ }^{36}$ Domingo de Cantabrana, incluso, emparentó con el conde de Baños, al parecer a través de una hermana de éste. ${ }^{37}$

En marzo de 1663, conde de Baños envió a Manila el galeón San José, con el socorro en dinero y 700 infantes, en cuyo despacho se gastaron poco más de 648,000 pesos. ${ }^{38}$ De acuerdo con los detractores del virrey, en esa ocasión remitió 150,000 pesos para comprar mercancías orientales, a cargo del capitán general de la nao, Francisco García del Fresno y del gobernador del archipiélago, el maestre de campo Diego de Salcedo, quien iba a tomar posesión de su cargo. ${ }^{39}$ Hasta donde sabemos, el general del galeón también recibió 3,000 pesos de Austasio Salcedo Benavides, uno de los favoritos del virrey, al que nombró corregidor de Metepec, lo protegió de las denuncias que hicieron los indios de su jurisdicción por los fraudes que cometía y, poco después, lo nombró corregidor de la ciudad de México. Otros miembros del gobierno que enviaron caudales en la nao San José para la compra de mercaderías asiáticas fueron el secretario de gobierno, quien invirtió 4,000 pesos, el contador de cuentas destinó 1,000 pesos, mientras que la viuda del contador de Manila canalizó 2,000 pesos. ${ }^{40}$

Al igual que los virreyes novohispanos, los gobernadores de Filipinas participaban de manera ilícita en el comercio del galeón de Manila. Esta y otras prácticas ilegales les permitían acumular grandes fortunas, circunstancia que hacía sumamente atractivo el desempeño de sus cargos. Diego de Salcedo había sido designado gobernador, capitán general y presidente de la audiencia de Filipinas, en diciembre de 1661. Es muy probable que, como se acostumbraba, hubiera pagado por dicho nombramiento para aliviar la grave situación que padecía el erario regio. ${ }^{41}$ Salcedo llegó a la ciudad de México alrededor del mes de octu-

36 Sentencia del Real Consejo de Indias sobre el Conde de Baños, en HANKE, op. cit., Pp. 216-298; GUIJO, op. cit., p. 200. 37 SÁNCHEZ TRUjILLANO, María Teresa. Los envíos de Indias. El arte colonial en la Rioja. Revista Anales del Museo de América, no. 9, 2001, pp. 255-274.

38 Papel en que se refieren los servicios que hizo a S.M. el conde de Baños, Juan de Leyva y de la Cerda, Ca. 1660, en HANKE, op. cit., p. 189.

39 Sentencia del Real Consejo de Indias sobre el Conde de Baños, en HANKE, op. cit., Pp. 216-298; Guijo, Diario, t. I, 1853 , p. 479.

40 ISRAEL, op. cit, PP. 264-265; RAGON, op. cit., p. 109. Sentencia del Real Consejo de Indias sobre el Conde de Baños, en HANKE, op. cit., PP. 216-298.

41 Hasta donde sabemos, en la administración del virrey marqués de Cerralvo (1624-1635) se vendió el cargo de gobernador de Filipinas por 28,000 pesos. Hoberman, Mexico's, 1991, p. 179. El gobernador Gabriel de Curuluzaegui y Arriola pago 4,000 pesos por su nombramiento; Fausto Cruzat y Góngora pago 50,000 pesos; Domingo de Zabalburu y Echaverri también contribuyó con 50,000 pesos. SANZ TAPIA, Ángel. ¿Corrupción o necesidad? La venta de cargos de gobierno indianos bajo Carlos II (1674-1700). Madrid: Consejo Superior de Investigaciones Científicas, 2009 , p. 161. 
bre de 1662, en donde permaneció hasta febrero de 1663. Con el respaldo del virrey, obtuvo del mismo Domingo Cantabrana dinero prestado para negociar bienes asiáticos, quien se lo otorgó como consignatario del general García del Fresno. Tras la muerte de Diego de Salcedo, acaecida en 1669, Cantabrana tuvo que acudir a los tribunales para que se le pagara el dinero que el difunto le debía, asunto que continuaba litigando en $1672 .{ }^{42}$

A fines de marzo de 1664 partió del puerto de Acapulco la nao Nuestra Señora de la Concepción. En el despacho de este navío con 374 soldados de mar y guerra, el virrey gastó 370.000 pesos del situado. ${ }^{43}$ La ambición y la hacienda de Leyva y de la Cerda se habían incrementado, de modo que en esta embarcación cargó 230,000 pesos para adquirir géneros asiáticos. En noviembre de 1665 arribó a Acapulco el galeón San José, que había partido rumbo a Manila, en marzo de 1663. Luis Roche venía a cargo de las mercancías que había comprado por comisión del virrey, las cuales llegaron consignadas a Domingo de Cantabrana. ${ }^{44}$ Presumimos que el mercader se hizo cargo de almacenarlas y venderlas, como debió haber sucedido en los años anteriores.

De acuerdo con la investigación de Ragon, el virrey Baños acumuló un gran patrimonio durante su administración, principalmente del tráfico con Filipinas. Por esta razón, el obispo de Puebla Diego Osorio de Escobar se refería al conde como "un mercader más en el reino". 45 Como vimos, según los testigos del juicio de residencia del conde, éste invirtió 450,000 pesos en la compra de bienes orientales, enorme suma que debió haberle generado beneficios muy elevados. Las actividades ilícitas y los abusos del virrey, aunados al conflicto que tuvo con el obispo de Puebla y administrador del arzobispado de México, dieron lugar a innumerables denuncias en su contra por lo que fue destituido, en 1664, en medio de grandes escándalos. En las ciudades de México y Puebla hubo manifestaciones públicas en su contra, no obstante, el conde permaneció en Nueva España aún después de haber entregado el gobierno a su sucesor. $^{46}$ Se sospechaba que Baños había prolongado su estancia en el virreinato, hasta marzo de 1666, para esperar el retorno de las mercancías que había mandado comprar en Manila. Sin embargo, de acuerdo con Hoberman, los retornos de las inversiones realizadas

42 Real cédula, Madrid, a 7 de noviembre de 1672. A.G.I., Filipinas, 5, N.556 y 341, L.7, fs. 153v-154v. año 1672.

43 Papel en que se refieren los servicios que hizo a S.M. el conde de Baños, Juan de Leyva y de la Cerda, Ca. 1660, en HANKE, op. cit., p. 189.

44 Sentencia del Real Consejo de Indias sobre el Conde de Baños, en HANKE, op. cit., PP. 216-298.

45 RAGON, op. cit., pp. 119-121, 122-123 y “¿Abusivo o corrupto?..., pp. 273-274.

46 Sobre la oposición que se generó en contra del conde de Baños, véase ISRAEL, op. cit., Pp. 265-268. 
en dicho comercio podían fluctuar entre los cuatro y los ocho años. ${ }^{47}$ Luego de la pública notoriedad de las actividades ilícitas que realizaron el virrey y su familia y del escándalo que generó al resistirse a abandonar su cargo, Baños cayó en el desprestigio total y no volvió a recibir ningún nombramiento. ${ }^{48}$

\section{CONCLUSIONES}

Los virreyes duque de Alburquerque y conde de Baños, sus familiares y criados, participaron de manera ilícita en el comercio Pacifico, al igual que sus familiares y criados, con el apoyo de los mercaderes más acaudalados del consulado de la ciudad de México. En abierta transgresión de la normatividad establecida, dichos mandatarios y sus allegados podían lucrar al tiempo que estimulaban los negocios de prominentes miembros del cuerpo mercantil. Las redes que éstos establecieron se extendieron, incluso, al ambito familiar. Para transportar los caudales y las mercancías que no estaban incluidas en las relaciones de la carga, dichos virreyes nombraban sus allegados como oficiales de los galeones. En el futuro habría que investigar qué otros mandatarios realizaban este tipo de prácticas.

Los gobernadores de Filipinas, al igual que los oidores, alcaldes del crimen y los oficiales de la real Hacienda del virreinato y el archipiélago, también participaban en el comercio transpacífico al margen de la ley. Vimos el caso del gobernador Diego de Salcedo, quien se alió con el virrey Baños y obtuvo apoyo financiero del mercader Domingo de Cantabrana. Además de realizar sus negocios personales, el virrey Baños atendió las instrucciones reales de apoyar a Filipinas con dinero soldados y armamento, para solventar la economía y la defensa de las islas. ${ }^{49}$

En compensación por los servicios que prestaban a los mandatarios y sus allegados, los mercaderes podían involucrarse en la intermediación en la venta de oficios, entre otros negocios de los virreyes. Asimismo, dichos mercaderes y sus familiares recibían nombramientos honoríficos y favores judiciales relacionados con la contratación de la plata sin quintar, el contrabando y el fraude en el pago de los derechos marítimos. Los miembros del consulado corrían muchos riesgos en el tráfico del galeón de Manila, especialmente al aso-

\section{HOBERMAN, op. cit., p. 63.}

48 Sentencia del Real Consejo de Indias sobre el Conde de Baños, en HANKE, op. cit., pP. 216-298.

49 Véase al respecto TATEIWA, Reiko. ¿El peor virrey de la Nueva España resultó ser un héroe de las Filipinas? Revisión del gobierno virreinal del conde de Baños (1660-1664), ponencia presentada en el Congreso de la FIEALC, 2003. 
ciarse y prestar grandes caudales de los funcionarios de la administración real que tenían gran poder e influencia en el virreinato y la corte real.

La participación de virreyes, gobernadores y otros funcionarios de Nueva España y Filipinas en el comercio transpacífico contribuyó a dinamizarlo cuando se encontraba en plena decadencia. A petición de los vecinos de Manila, que padecían por las severas restricciones impuestas a dicho comercio, la corona estuvo dispuesta a flexibilizar la normatividad que lo regía. 